\title{
THE ECONOMICS OF LUCKINESS: HOW CRAZY ARE MALAYSIAN CHINESE TOWARDS CAR PLATE NUMBER "8”?
}

\author{
HOCK-EAM LIM \\ WOEI-CHYUAN WONG \\ NUR ADIANA HIAU ABDULLAH \\ School of Economics, Finance and Banking \\ Universiti Utara Malaysia
}

\begin{abstract}
The Chinese society is well-known for its obsession towards number "8". Eight is the luckiest number to the Chinese as its pronunciation resembles the meaning of prosperity, wealth or fortune. Prior research estimating the marginal effect of " 8 " on winning bid prices of car plate numbers attributes the positive impact of " 8 " on bid prices to superstitious value. However, the estimated positive effect could also be attributed to Veblen goods and future resale consideration. Thus, an upward bias might exist in prior research's estimation. This study aimed to circumvent this issue by comparing the marginal effect of all "8" car plate numbers of Malaysian Chinese bidders and their non-Chinese counterparts who are neutral towards number "8". Descriptive statistics results reveal that the majority of all " 8 " plates are won by Chinese bidders. However, regression results reveal that Chinese bidders have a lower estimated marginal effect of number eight than their non-Chinese counterparts. This implies that while number " 8 " is popular among the Chinese, this popularity does not translate into higher bidding prices. These findings suggest the roles of Veblen goods and future resale consideration should not be ignored in estimating the superstitious value in car plate numbers.
\end{abstract}

Keywords: Car plate number, Superstitions in number, Veblen good effect.

\section{Introduction}

The term superstition is derived from the Latin word of "supersisto" which literally means "the one who over-stands" or "the one who is not progressive" (Sharivastav \& Kotnala, 2015). Based on a qualitative study, Delacroix and Guillard (2008) provided a comprehensive definition of superstitions: "beliefs and/or practices that have no religious nor scientific foundations and which lead people to think that certain facts (external events or one's own actions), or objects can bring good or bad luck, or be signs announcing positive or negative consequences". Superstitions are found to be linked with the external locus of control (Sagone and De Caroli, 2014), fear or anxiety (Wolfradt,
1997), ignorance (Krajewska-Kulak et al., 2011), religiosity (Torgler, 2003), confidence level and socio-economic status (Sharivastav \& Kotnala, 2015), and socio-demographic factors such as gender (females tend to be more superstitious than males - see Dag, 1999).

Superstitious beliefs have been long rooted since the beginning of human civilizations. Despite the rapid progress in sciences and technology, superstitions still prevail in modern societies of various cultures (Sharivastav \& Kotnala, 2015; Newport \& Strausberg, 2001). The Chinese society is well known for its numerological belief. This is evidenced by the publication of the Book of Changes (Yijing) dated back to more than two thousand years ago, that provides an 
in-depth analysis of numbers. ${ }^{1}$ The odd numbers $(1,3,5,7,9)$ are pre-described as forces of "Yang" (male), whereas the even numbers $(2,4,6,8)$ are associated with the forces of "Yin" (female). The combination of "Yin" and "Yang" produces the Eight Diagrams and Five Elements that in turn, generate a system that harmonizes human beings with their surrounding environments.

Although the Book of Changes produces the first numerological analysis in Chinese society, Chinese superstitious belief in numbers is not based on this analysis. Lucky and unlucky numbers, according to the Chinese, are based merely on the pronunciation of these numbers. For example, number " 4 " that is pronounced similar to the word "death" is considered to be an unlucky number. The desire to avoid number "4" is manifested in the action of not labelling the "fourth" floor for hospitals in Taiwan (Lin, Lin, \& Lee, 2014). This is to give a peace of mind to the staff, patients and their families that tend to associate number "4" with "death".

On the other hand, the number " 8 ", the pronunciation of which carries the meaning of "prosperity, wealth, or fortune" is considered to be the luckiest number (Yau, 2015). The "craziness" of the Chinese towards number " 8 " could be seen from their willingness to pay for this number. Some of the examples are as follows: A phone number of 8888-8888 cost around USD350,000 to the Sichuan Airlines of China; the Chinese government launched the Beijing Summer Olympics at $8.08 \mathrm{pm}, 8$ February; a Chinese driver paid RMB 1 million (around USD145,000) for the number plate 88888 to be used on his vehicle valued at just RMB 30,000 (around USD4,000) (Wang, 2016; Lim, Wong, \& Abdullah, 2016). In Malaysia,

Book of Changes, is also known as "Yijing". "Yi" literally means "changes" and "jing" means "books". It is a classical book from the early history of China. Its origin can be traced back to the Bronze Age of the Zhou Dynasty in China. This book describes the endless transformation and dynamic changes of all things and situations in this world. The changes are presented in terms of hexagram transformation that consists of 64 combinations of numbers. See Nelson (2011) for a detailed discussion. the frequency of number " 8 " appearing on a car plate is positively associated with winning bid prices (Wong, Abdullah, \& Lim, 2017). Indeed, one could easily find numerous examples of the "craziness" of the Chinese towards number " 8 ".

The superstitious value of number " 8 " has been studied and is in the literature on car plate numbers and housing. ${ }^{2}$ These studies refer to Fudenberg and Levine is (2006) theoretical model to form their superstition hypotheses. Specifically, Fudenberg and Levine (2006) theorize that superstitious beliefs can persist if their probability of being exposed as untrue is sufficiently low. An empirical implication from this theory is that superstitious beliefs can persist and can affect human behaviour, hence pricing. The hedonic regression model is normally used to capture the impact of superstitions on prices where findings of the positive and significant impacts of number " 8 " on prices are interpreted as supporting evidence for superstitious beliefs. $\mathrm{Ng}$, Chong, and Du (2010), Chong and Du (2008), and Woo et al. (2008) for instance, found that the occurrence of number " 8 " on a car plate has a positive and significant effect on the car plate winning bid prices in Hong Kong. Similar findings were found in Malaysia (Wong, Abdullah, \& Lim, 2017). These authors relate the positive impact of number " 8 " on Chinese superstitious beliefs that welcome number " 8 " and avoid number "4".

However, the positive and significant marginal effects of number " 8 " cannot be explained solely by superstition motives. Ng, Chong, and Du (2010) pointed out that lucky car plate numbers could also serve as Veblen good (also known as conspicuous good) for the buyers to signal their high income and greater social status. Furthermore, the positive impact of number " 8 " could be a manifestation of its future resale value. For example, used cars with lucky number plates, all else being equal, can be

2 In the housing literature, Bourassa and Peng (1999), Chau et al. (2001), Liu and Wong (2012) found evidences on the positive (negative) impact of house addresses that contained number " 8 " ("4") on house prices in New Zealand, Hong Kong and Singapore, respectively. 
sold at higher prices and in a shorter duration as compared to other used cars with normal plate numbers. Thus, due to the future resale consideration, a prospective bidder might be willing to pay more for a lucky plate number. In short, the positive and marginal effects of number " 8 " on prices could be attributed to three factors: superstitions, conspicuous good, and future resale consideration. There is a potential for an upward bias in estimating the value of superstitions if the other two factors are not properly controlled.

Previous studies used different model specifications to control the effect of conspicuous good and future resale consideration. For example, Ng, Chong, and Du (2010) estimated the models with 3-digit and 4-digit car plate numbers separately in order to control for conspicuous good and future resale consideration effects in estimating superstition value. These authors concluded that values of superstition in numbers are still prevalent among the Chinese society based on the positive and significant impact of lucky numbers (including number " 8 ") on winning bid prices. The conclusion is however, not convincing. This is because the Chinese who attach heavy emphasis on wealth accumulation and material possession are more likely to pay for the conspicuous and resale consideration effects in lucky plate numbers rather than to satisfy their superstitious belief. The primitive superstition (i.e. a total belief on the mistaken causal link between two independent events such as the possession of number " 8 " will bring good fortune) postulated by Delacroix and Valerie (2008) does not fit the Chinese living in a modern society.

In this context, the positive and significant effects of Veblen good and future resale consideration could be mistaken as the value of superstitions. Thus, it is imperative to evaluate the potential upward bias efficiently. The statistical control approach that was employed by previous studies could be efficient if all the major factors that influence pricing are taken into consideration together with their interactive effects. Omission of any of the major factors will lead to an upward bias in the estimated superstition value.
In this paper, we shed more light to this line of literature by proposing a "natural experimental" approach that provides a better control on the upward bias in superstition value. By doing this, we are able to provide a better estimation for the value of superstitions.

The Malaysian car plate auctioning market provides a natural experiment to distinguish the impact of superstition from non-superstition (conspicuous and resale) effects. Malaysia's three main ethnic groups (Chinese, Indian and Malay) allow us to compare the Chinese and nonChinese bidders' preferences and willingness to pay for number " 8 ". For the Chinese, number "8" is considered as the luckiest number; whereas the Malays and Indians treat number "8" as a neutral number. This would mean for the Malays and Indians, their willingness to pay more for number " 8 " should be purely due to the effect of conspicuous consumption and resale consideration. Thus, the Chinese bidders could serve as the "treatment" group while the nonChinese (Malay and Indian) are the "control" group in examining the superstition value in number " 8 ".

\section{Data and Methodology}

\section{Data}

The data used in the present study were collected from the first-price sealed bid auction of the Malaysian Road Transportation Department (Jabatan Pengangkutan Jalan Malaysia, JPJ). The auction is used for bidders to bid for the selected special car plate numbers which are divided into three categories. First, the golden numbers that consist of numbers 1 to 10 with a reserve price of RM10,000. Second, the attractive numbers that consist of 37 selected numbers with a reserve price of RM1,000. Third, the popular numbers that consist of 414 selected numbers with a reserve price of RM300. The other nonspecial car plate numbers are sold at RM300 on a first come first served basis over the counter (no bidding).

Altogether, the data consisted of 10,834 winning bid results in the states of Kedah and Penang in 
Malaysia, between the years 2011 and 2013. We observed the plate number, the auction year, the winning bid price and the bidders' profiles such as race, age and gender. Table $1 \mathrm{a}$ and $1 \mathrm{~b}$ provide the sample characteristics. Chinese winning bidders consisted of more than half (54.99\%) of the sample. This was followed by the Malays $(41.21 \%)$ and Indians $(3.80 \%)$. The average age of the winning bidders was 40 years old and more than half of them $(66 \%)$ were males. The average winning bidding price was RM2219.36.

Table 1a

Sample Characteristics I

\begin{tabular}{lcc}
\hline & Freq & $\%$ \\
\hline Malay & 4497 & 41.21 \\
Chinese & 6001 & 54.99 \\
Indian & 415 & 3.80 \\
\hline TOTAL & 10913 & 100 \\
\hline
\end{tabular}

Table $1 b$

Sample Characteristics II

\begin{tabular}{lrc}
\hline & Mean & Std Dev. \\
\hline Reserve price (R) & 901.61 & 1927.69 \\
Bid price (B) & 2219.36 & 6121.76 \\
Premium (B-R) & 1334.37 & 4665.58 \\
Age & 40.02 & 11.29 \\
Male & 0.66 & 0.47 \\
\hline
\end{tabular}

\section{Methods}

The comparative approach was used to estimate the Chinese's superstition value in number " 8 ". The Chinese sub-sample (who treat " 8 " as the luckiest number) is compared to the Malay and Indian sub-samples (who treat eight as a neutral number). We computed the bid premium for each winning bid by taking the difference between the winning bid price and the reserve price. For the Chinese sub-sample, the price premium in number " 8 " could be attributed to the three sources of premium discussed earlier (superstitions, conspicuous good and future resale consideration); for the Malay and Indian sub-samples, it could be attributed to conspicuous good and future resale consideration but not superstitions.

Descriptive and econometrics analysis were applied into the three sub-samples (Chinese, Malay and Indian). Descriptive analysis was employed to provide a preliminary analysis on the bid premium paid to number " 8 ". Econometrics analysis was then used to estimate the marginal effects of number " 8 " on the winning bid premium. We focused our analysis on four types of all " 8 " plates, i.e. one digit (e.g. PKH8), two digits (PKH88), three digits (PKH888), and four digits (PKH8888). The control variables included in the regression were bidders' gender and age. The Tobit model was employed because of the lower censoring point at RM300 (reserve price). 


\section{Results and Analysis}

\section{Descriptive statistics analysis}

Table 2 presents the summary statistics for reserve price, bid price, bid premium, bidder's age and bidder's gender segregated by the bidder's ethnicity. Overall, the Chinese and
Indian bidder's exhibit a substantially higher winning bid price and bid premium than their Malay counterparts. The average bidder's age is almost similar across the ethnic groups. In terms of gender, Indians are found to have the highest percentage of male bidders $(72 \%)$.

Table 2

Descriptive Statistics

\begin{tabular}{lrrr}
\hline & Chinese & Malay & Indian \\
\hline Reserve price (R) & 1019.80 & 729.91 & 1016.87 \\
Bid price (B) & 2584.82 & 1696.70 & 2551.70 \\
Bid premium (B-R) & 1584.68 & 979.16 & 1554.51 \\
Age & 40.47 & 39.47 & 39.50 \\
Male & 0.64 & 0.68 & 0.72 \\
\hline
\end{tabular}

Table 3 presents the frequency of all " 8 " plates by bidder's ethnicity. The proportion of Chinese bidders for all " 8 " plates which range from $68.09 \%$ to $78.26 \%$ is significantly higher than their sample mean of $55 \%$. This finding highlights the popularity of number " 8 " among Chinese bidders in our sample. The proportion of Chinese and non-Chinese bidders is however, more balanced for other non-all " 8 " plates at a ratio of 55:45.

Table 3

Frequency of All "8" Plate Numbers

\begin{tabular}{lrrrrrrrrr}
\hline & \multicolumn{1}{c}{ Overall } & \multicolumn{3}{c}{ Chinese } & \multicolumn{3}{c}{ Malay } & \multicolumn{3}{c}{ India } \\
\cline { 2 - 11 } & freq. & $\%$ & freq. & $\%$ & freq. & $\%$ & freq. & $\%$ \\
\hline All "8" plate numbers & & & & & & & & & \\
One-digit (8) & 48 & 100 & 37 & 77.08 & 9 & 18.75 & 2 & 4.17 \\
Two digits (88) & 50 & 100 & 38 & 76.00 & 11 & 22.00 & 1 & 2.00 \\
Three digits (888) & 46 & 100 & 36 & 78.26 & 9 & 19.57 & 1 & 2.17 \\
Four digits (8888) & 47 & 100 & 32 & 68.09 & 11 & 23.40 & 4 & 8.51 \\
Other plate numbers & 10732 & 100 & 5858 & 54.58 & 4457 & 41.53 & 407 & 3.79 \\
\hline
\end{tabular}

In terms of the willingness to pay, the bid price and bid premium were cross-tabulated by bidders' ethnicity and the types of all "8" plates. The results are as shown in Table 4. On average, Chinese bidders paid a higher bid premium (or bid price) for three-digit (888) plates as compared to non-Chinese bidders. However, the bid premium paid by the Chinese bidders was found to be the lowest for the one digit (8) and two digit (88) plates. On the other hand, the Malays had the highest bid (or bid price) for four digit (8888) plates; and the Indians had the 
highest premium paid on the one digit (8) and two digit (88) plates. Thus, it is found that the Malay and Indian bidders who do not hold any superstitious belief towards number "8" were in fact paying more for this number than their superstitious Chinese counterparts (except in the three-digit [888 ] plates).

Table 4

Age, Gender and Prices by "Eight” (8)

\begin{tabular}{lrrrrr}
\hline & \multicolumn{3}{c}{ All "eight" (8) in the car plate number } & \multirow{2}{*}{$\begin{array}{c}\text { Other plate } \\
\text { numbers }\end{array}$} \\
\cline { 2 - 5 } & one digit (8) & two digits (88) & three digits (888) & four digits (8888) & \\
\hline Chinese & & & & & \\
Bid price (B) & 26646.14 & 11452.58 & 5644.89 & 4085.56 & 2348.32 \\
Premium (B-R) & 16646.14 & 9452.58 & 3644.89 & 2085.56 & 1421.44 \\
Age & 39.81 & 43.00 & 40.11 & 41.75 & 40.45 \\
Male & 0.68 & 0.68 & 0.58 & 0.72 & 0.64 \\
\hline Malay & & & & & \\
Bid price (B) & 26878.67 & 12134.36 & 5433.33 & 4896.00 & 1604.65 \\
Premium (B-R) & 16878.67 & 10134.36 & 3433.33 & 2896.00 & 914.11 \\
Age & 41.89 & 40.91 & 44.56 & 41.36 & 39.44 \\
Male & 1.00 & 0.82 & 0.89 & 0.82 & 0.68 \\
\hline Indian & & & & & \\
Bid price (B) & 32750.50 & 12800.00 & 5510.00 & 3875.00 & 2357.85 \\
Premium (B-R) & 22750.50 & 10800.00 & 3510.00 & 1875.00 & 1418.00 \\
Age & 52.00 & 34.00 & 18.00 & 41.25 & 39.49 \\
Male & 0.50 & 1.00 & 1.00 & 0.75 & 0.71 \\
\hline
\end{tabular}

In short, results of the descriptive analysis show that the Chinese bidders won most of the all " 8 " plates. However, the premium paid by the Chinese bidders was lower than the Malay and Indian bidders (except for the three-digit [888] plates). There are Malay and Indian bidders who paid higher premiums for number " 8 " than the Chinese bidders. To gain further insight into this disparity in willingness to pay for number " 8 ", the marginal effects of number " 8 " among the Chinese, Malays and Indians are estimated and compared in the following section.

\section{Regression analysis}

Table 5 presents the estimated Tobit models (bid premium as the dependent variable) for the subsamples of Chinese, Malay and Indian bidders.
Please refer to Appendix 1 for the details of the estimated models. Statistically, the estimated models are found to be fit with the sample as shown by the p-values that are almost equal to zero for the overall fit tests. In Table 5, the estimated marginal effects of number " 8 " are found to be positive and significant across the three sub-samples (Chinese, Malay and Indian). Among the four types of all " 8 " plates, one digit (8) has the largest marginal effect. This is followed by the two digits (88), three digits (888) and four digits (8888). The differences in marginal effect are consistent with the conspicuous consumption effect where lower digit plates, due to their rarity and uniqueness (signal of high social status), tend to command higher prices. 
Comparing the marginal effect of all " 8 " plates across the three sub-samples (by bidders' ethnicity), it is found that the Indian sub-sample has the largest marginal effect in the one digit (8), two digits (88) and three digits (888) plates. The Malay sub-sample has the largest marginal effect in the four digits (8888) plates. Surprisingly, the marginal effect of the Chinese sub-sample is found to be lower than the other ethnic groups. The Hausman tests reveal the differences in the estimated marginal effect (between the Chinese and the Malays and between the Chinese and the Indians) are significant at the $1 \%$ level (see Table 5). Thus, Chinese bidders do not pay a higher premium for all " 8 " plates than the Malay or Indian bidders.

Table 5

The estimated Tobit Models

\begin{tabular}{|c|c|c|c|c|c|c|}
\hline & \multicolumn{2}{|l|}{ Chinese } & \multicolumn{2}{|l|}{ Malay } & \multicolumn{2}{|l|}{ Indian } \\
\hline & Coeff. & P-value & Coeff. & P-value & Coeff. & P-value \\
\hline \multicolumn{7}{|l|}{ All "8" plate numbers } \\
\hline One digit (8) & $15928.74 * * *$ & 0.000 & $16386.66^{* * *}$ & 0.000 & $21829.10 * * *$ & 0.000 \\
\hline Two digits (88) & $8670.01 * * *$ & 0.000 & $9736.05 * * *$ & 0.000 & $10426.20 * * *$ & 0.000 \\
\hline Three digits (888) & $2773.56 * * *$ & 0.000 & $2599.57 * * *$ & 0.004 & $4216.90 * * *$ & 0.000 \\
\hline Four digits (8888) & $1078.51 * * *$ & 0.007 & $2479.81 * * *$ & 0.000 & $1345.60 * *$ & 0.020 \\
\hline Age & $19.36 * * *$ & 0.004 & $39.33 * * *$ & 0.000 & $67.54 * *$ & 0.048 \\
\hline Male & $401.09 * * *$ & 0.006 & $303.38 * * *$ & 0.010 & $1336.36^{* *}$ & 0.017 \\
\hline Cons & -324.44 & 0.277 & $-1458.92 * * *$ & 0.000 & $-3259.04 *$ & 0.053 \\
\hline 1. Obs & 5941 & & 4452 & & 410 & \\
\hline $\begin{array}{l}\text { 2. Overall fit test } \\
\text { (p-value) }\end{array}$ & $0.000 * * *$ & & $0.000 * * *$ & & $0.000 * * *$ & \\
\hline \multicolumn{7}{|l|}{$\begin{array}{l}\text { 3. Hausman test on } \\
\text { coeff. diff. (p-value) }\end{array}$} \\
\hline Chinese vs Malays & $0.000 * * *$ & & $0.000 * * *$ & & $0.000 * * *$ & \\
\hline Chinese vs Indians & $0.000 * * *$ & & $0.000 * * *$ & & $0.000 * * *$ & \\
\hline
\end{tabular}

In order to evaluate the nonlinear (quadratic) effect of the age variable on the bid premium, we re-estimate the models in Table 5 with the presence of age and age squared (see Appendix 2 ). There are no noticeable changes to the estimated coefficient of all "8"-plate variables and gender. However, the age variables (age and age squared) turn insignificant when they are included in the models. This might be due to the multicollinearity between age and age squared as indicated by the values of VIF that are more than 10 and the significance of the restriction test on age and age squared.

\section{DISCUSSIONS AND CONCLUSION}

This paper aimed to estimate the superstition value of the Malaysian Chinese to number "8" using a comparison approach. The existence of Chinese, Malay and Indian ethnicities that do not share common preferences toward number "8" provide a natural experiment to estimate the Malaysian Chinese superstition value. Chinese are found to win most of the auctioned all "8" plates (68\%-78\%). This finding indicates the popularity of number " 8 " among Chinese bidders in our sample. However, the obsession 
towards number " 8 " by the Chinese bidders does not translate into a higher winning bid premium as compared to non-Chinese bidders. The estimated marginal effects for all " 8 " plates reveal that the Chinese bidders are in fact paying a significantly lower bid premium than the Malay and Indian bidders. Thus, our findings do not support anecdotal evidences which showed Chinese bidders to be "crazy" (irrational/superstitious) about number " 8 ". This finding has one important implication, that is, the effects of conspicuous good and future resale consideration for number " 8 " are lower for the Chinese than the Malays or the Indians. One plausible explanation is that the Malay or Indian bidders could have overvalued the effects of conspicuous good and the resale prospect of number "8" plates, or it could be that the Chinese bidders have undervalued the effects. The role of conspicuous good and future resale consideration should not be ignored in estimating the superstition value of a number eight car plate. There is an important caveat to the above findings. In estimating the value of superstitions, due to data limitation, the estimated model could only control bidders' demographic variables (age and gender). Other variables such as employment status, educational and family background, are ignored. It is suggested that future research should explore more into this limitation.

\section{Acknowledgement}

We would like to thank the Ministry of Higher Education Malaysia and Universiti Utara Malaysia for providing financial support for this study through the Fundamental Research Grant Scheme (S/O Code: 13018). Our gratitude is also extended to the anonymous referee whose comments have improved this paper substantially.

\section{References}

Bourassa, SC, \& VS Peng. (1999). Hedonic prices and house numbers: The influence of feng shui. International Real Estate Review, 2(1), 79-93.
Chau, KW., VSM Ma, \& DCW., Ho, D. (2001). The pricing of luckiness in the apartment market. Journal of Real Estate Literature, 9(1), 29-40.

Dag, I. (1999). The relationships among paranormal beliefs, locus of control and psychopathology in a Turkish college sample. Personality and Individual Differences, 26, 723-737.

Delacroix, E., \& Guillard, V. (2008). Understanding, defining and measuring the trait of superstition. Online paper. Retrieved from https://www. researchgate.net/publication/41221415_ Understanding_defining_and_ measuring_the_trait_of_superstition

Krajewska-Kulak, E., Kulak, W., Radziejawski, P., Rozwadowska, E., Lankau, A., Kowalewska, B., Kondzior, D., SzyszkoPerlowska, A., Krajewska-Ferishah, K., Ortman, E., \& Moczydlowska, A. (2011). Current view of traditional superstitions in general population of Podlaskie province. Progress in Health Sciences, 1(2), 76-83.

Long, S. (1997). Regression models for categorical and limited dependent variables. Advanced Quantitative Techniques in the Social Sciences Number 7. Sage Publications: Thousand Oaks, CA.

Lim, H. E., Wong, W.C., \& Abdullah, N.A.H. (2016, January). The economics of luckiness among Chinese in Malaysia: What is the value of superstition in car plate number of " 8 "? Paper presented at the Asian American Conference for Academic Disciplines 2016, Singapore.

Lin, F-Y., Lin, H-R., \& Lee, T-Y. (2014). Workplace beliefs about luck among Taiwanese nurses. Journal of Nursing, $1,1-7$.

Liu, H., \& WK., Wong. (2012). Can superstitious beliefs affect market equilibrium? Personal beliefs and beliefs about others. Working paper, National University of Singapore.

Nelson, S. E. (2011). The Yijing and philosophy: From Leibniz to Derrida. Journal of Chinese Philosophy, 38 (3), 377-396.

Newport, F., \& Strausberg, M. (2001). 
Americans' belief in psychic and paranormal phenomena is up over last decade. Princeton: Gallup News Service.

Ng, T., Chong, T., \& Du, X. (2010). The value of superstitions. Journal of Economic Psychology, 31(3), 293-309.

Sagone, E., \& De Caroli, M. E. (2014). Locus of control and beliefs about superstition and luck in adolescents: What's their relationship? Procedia - Social and Behavioral Sciences, 140, 318-323.

Sharivastav, M., \& Kotnala, A. (2015). Psycho-social factors contributing to superstitious behaviour: Literature review. International Journal of Research - Granthaalayah, 3(5), 42-47.

Skinner, B. F. (1948). Superstition in the pigeon. Journal of Experimental Psychology, 38, 168-172.

Torgler, B. (2003). It is about believing: Superstition and religiosity. Working paper No. 2003-10. Basel: Center for Research in Economics, Management and the Arts (CREMA).

Wang, S. (2016). Driver pays 1 million RMB for 'lucky' 88888 license plate, gets pulled over 8 times in one day. Shanghaiist Online News, Jun 29, 2016. Retrieved from http://shanghaiist.com/2016/06/29/ lucky_license_plate_backfires.php

Wang, A. (2011). Superstition still widespread in high-tech Asia. AsiaOne News, Feb 27, 2011. Retrieved from http://news. asiaone.com/News/Latest+News/Asia/ Story/A1Story20110227-265543.html

Wolfradt, U. (1997). Dissociative experiences, trait anxiety and paranormal beliefs. Personality and Individual Differences, 23, 15-19.

Wong, W. C., Abdullah, N. A. H., \& Lim, H. E. (2017, May). Malaysian Chinese superstitions value: Evidence car plate auctioning. Paper presented at the 19th Malaysian Finance Association Conference. Perak, Malaysia: Universiti Tunku Abdul Rahman (UTAR).

Yau, H. T. A. (2015). To be or not to be superstitious - that's the question. Procedia - Social and Behavioural Sciences, 208, 5-12. 


\section{APPENDIX 1}

\section{THE ESTIMATED MODELS}

\section{Chinese}

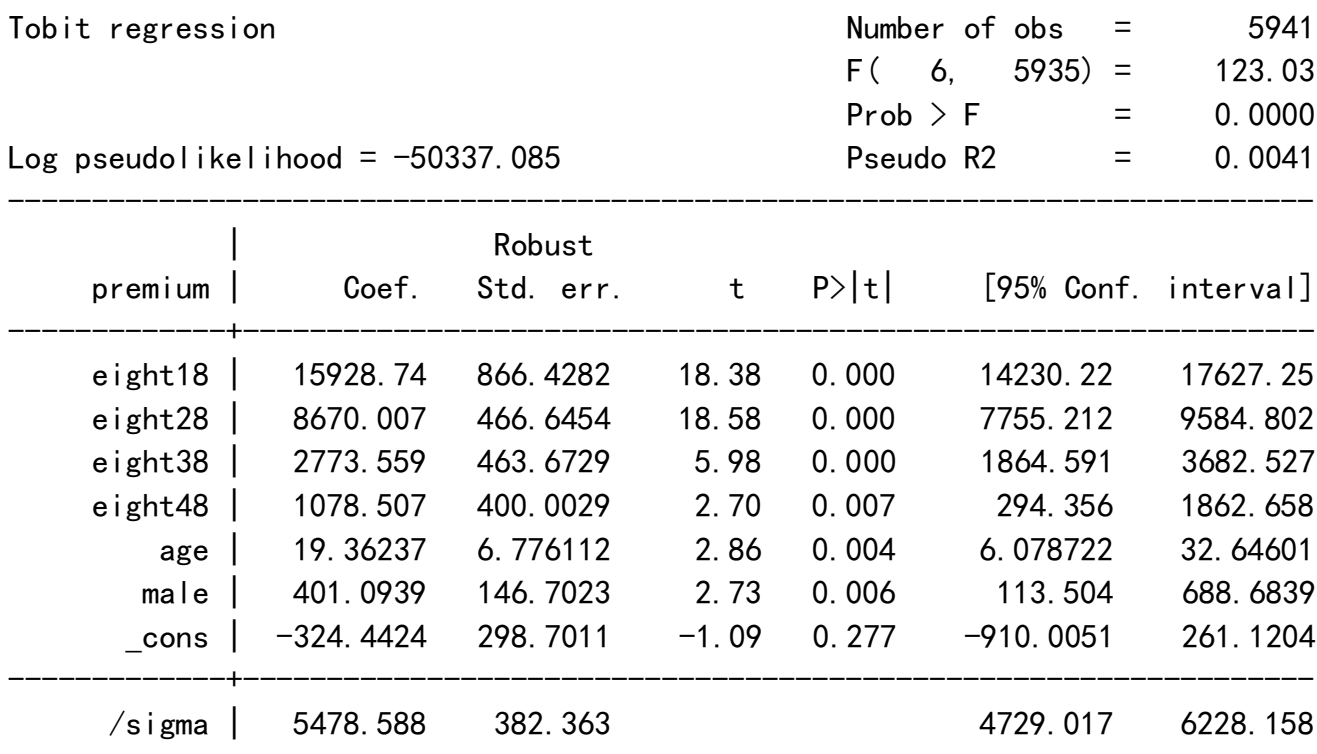

Obs. summary:

$$
\begin{aligned}
& 995 \text { left-censored observations at premium } \angle=0 \\
& 4946 \text { uncensored observations } \\
& 0 \text { right-censored observations }
\end{aligned}
$$

\section{Malay}

Tobit regression

$\begin{array}{llr}\text { Number of obs } & & 4452 \\ \mathrm{~F}(6, \quad 4446) & = & 59.01 \\ \text { Prob > F } & =0.0000 \\ \text { Pseudo R2 } & = & 0.0034\end{array}$

Log pseudolikelihood $=-35984.939$

\begin{tabular}{|c|c|c|c|c|c|c|}
\hline eight18 | & 16386.66 & 1462. 314 & 11.21 & 0.000 & 13519. 79 & 19253.52 \\
\hline e ight28 & 9736.05 & 839.7853 & 11.59 & 0.000 & 8089.653 & 11382.45 \\
\hline e ight38 & 2599.572 & 906.6011 & 2. 87 & 0.004 & 822. 1828 & 4376. 962 \\
\hline e ight48 & 2479.809 & 404. 1195 & 6. 14 & 0.000 & 1687.533 & 3272.084 \\
\hline age & 39. 33135 & 6. 504148 & 6. 05 & 0.000 & 26.57998 & 52. 08271 \\
\hline male | & 303. 3831 & 117. 4073 & 2. 58 & 0.010 & 73. 20633 & 533.56 \\
\hline _cons | & -1458.919 & 280.2993 & -5.20 & 0.000 & -2008.445 & -909.3925 \\
\hline /sigma & 4225. 333 & 409. 9475 & & & 3421.632 & 5029.034 \\
\hline
\end{tabular}

Robust

premium $\mid$ Coef. Std. err. $t \quad P>|t| \quad$ [95\% Conf. interval]

Obs. summary: $\quad 829$ left-censored observations at premium $<=0$

3623 uncensored observations

0 right-censored observations 


\section{Indian}

Tobit regression

$\begin{array}{llr}\text { Number of obs } & & 410 \\ \mathrm{~F}(5, \quad 404) & & . \\ \text { Prob }>\mathrm{F} & = & . \\ \text { Pseudo R2 } & = & 0.0052\end{array}$

Log pseudolikelihood $=-3365.9825$

Pseudo R2=

0052

\begin{tabular}{r|rrrrrr} 
& \multicolumn{7}{c}{$\begin{array}{c}\text { Robust } \\
\text { premium }\end{array}$} & Coef. & Std. err. & $\mathrm{t}$ & $\mathrm{P}\rangle|\mathrm{t}|$ & {$[95 \%$ Conf. } & interval] \\
\hline e ight18 & 21829.1 & 2572.315 & 8.49 & 0.000 & 16772.3 & 26885.89 \\
e ight28 & 10426.2 & 279.7837 & 37.27 & 0.000 & 9876.189 & 10976.22 \\
e ight38 & 4216.9 & 720.9009 & 5.85 & 0.000 & 2799.715 & 5634.086 \\
e ight48 & 1345.601 & 575.6421 & 2.34 & 0.020 & 213.9733 & 2477.229 \\
age | & 67.5436 & 34.05146 & 1.98 & 0.048 & .6034363 & 134.4838 \\
male & 1336.358 & 558.9089 & 2.39 & 0.017 & 237.6253 & 2435.091 \\
cons | & -3259.043 & 1676.219 & -1.94 & 0.053 & -6554.245 & 36.15813 \\
/sigma | & 6329.841 & 1670.478 & & & 3045.926 & 9613.755 \\
\hline
\end{tabular}

Obs. summary:

85 left-censored observations at premium $<=0$

325 uncensored observations

0 right-censored observations 


\section{APPENDIX 2}

THE ESTIMATED MODELS WITH AGE AND AGE SQUARED

\begin{tabular}{|c|c|c|c|}
\hline & Chinese & Malay & Indian \\
\hline & Coeff. & Coeff. & Coeff. \\
\hline \multicolumn{4}{|l|}{ All “eight” (8) in: } \\
\hline one digit (8) & $15919.16^{* * *}$ & $16404.55^{* * *}$ & $21637.18 * * *$ \\
\hline two digits (88) & $8676.29 * * *$ & $9744.47 * * *$ & $10452.82 *$ \\
\hline three digits (888) & $2761.52 * * *$ & $2602.08 *$ & 4028.17 \\
\hline four digits (8888) & 1113.19 & $2493.36^{*}$ & 1365.78 \\
\hline age & 61.37 & 20.03 & 32.23 \\
\hline age squared & -0.49 & 0.23 & 0.42 \\
\hline male & $402.87 * * *$ & $302.17 * * *$ & $1335.93 *$ \\
\hline _cons & -1164.29 & -1089.3 & -2570.43 \\
\hline Obs & 5941 & 4452 & 410 \\
\hline Overall fit test (p-value) & $0.000 * * *$ & $0.000 * * *$ & $0.000 * * *$ \\
\hline \multicolumn{4}{|c|}{ Hausman test on coeff. Differences (p-value): } \\
\hline Chinese vs Malays & $0.000 * * *$ & $0.000 * * *$ & $0.000 * * *$ \\
\hline Chinese vs Indians & $0.000 * * *$ & $0.000 * * *$ & $0.000 * * *$ \\
\hline VIF & 1 to 35.12 & 1 to 38.61 & 1 to 50.90 \\
\hline Restriction test (age and age squared) & $0.0052 * * *$ & $0.0000 * * *$ & $0.0731 *$ \\
\hline
\end{tabular}

